University of Wollongong

Research Online

Faculty of Informatics - Papers (Archive)

Faculty of Engineering and Information

Sciences

January 2002

\title{
Ripple signal amplification in distribution systems: a case study
}

\author{
B. S. Perera \\ University of Wollongong \\ K. Nguyen \\ Integral Energy, Australia \\ V. J. Gosbell \\ University of Wollongong, vgosbell@uow.edu.au \\ N. Browne \\ Integral Energy, Australia \\ S. Elphick \\ University of Wollongong, elpho@uow.edu.au
}

See next page for additional authors

Follow this and additional works at: https://ro.uow.edu.au/infopapers

Part of the Physical Sciences and Mathematics Commons

\section{Recommended Citation}

Perera, B. S.; Nguyen, K.; Gosbell, V. J.; Browne, N.; Elphick, S.; and Stones, J.: Ripple signal amplification in distribution systems: a case study 2002.

https://ro.uow.edu.au/infopapers/181

Research Online is the open access institutional repository for the University of Wollongong. For further information contact the UOW Library: research-pubs@uow.edu.au 


\title{
Ripple signal amplification in distribution systems: a case study
}

\begin{abstract}
Use of high frequency ripple signals for the control of loads such as off-peak hot water systems and street lighting systems is common within distribution utilities. Although injected signal levels are small and within stipulated limits, in distribution systems dominated by underground cables the signal levels received at the load ends can be relatively large due to resonance. One significant problem associated with the excessive signal levels is racing digital clocks caused by the additional zero crossings of the mains waveform. This paper presents the results from a detailed modelling study undertaken on a $22 \mathrm{kV}$ system. The dependency of the results on LV aggregate load models used and the damping provided by the lines and loads are discussed. Mitigation techniques suggested to control excessive signal levels are also investigated.

\section{Keywords}

damping, interference, load regulation, power distribution control, power supply quality, resonance, signal detection, underground distribution systems

Disciplines

Physical Sciences and Mathematics

\section{Publication Details}

This paper originally appeared as: Perera, BS, Nguyen, K, Gosbell, VJ et al, Ripple signal amplification in distribution systems: a case study, 10th International Conference on Harmonics and Quality of Power, 2002, vol 1, 93-98. Copyright IEEE 2002.
\end{abstract}

\section{Authors}

B. S. Perera, K. Nguyen, V. J. Gosbell, N. Browne, S. Elphick, and J. Stones 


\title{
Ripple Signal Amplification in Distribution Systems: A Case Study
}

\author{
B. S. P. Perera, Member, IEEE, K. Nguyen, V. J. Gosbell, Member, IEEE, N. Browne, Member, IEEE, \\ S. Elphick, J. Stones, Student Member, IEEE
}

\begin{abstract}
Use of high frequency ripple signals for the control of loads such as off-peak hot water systems and street lighting systems is common within distribution utilities. Although injected signal levels are small and within stipulated limits, in distribution systems dominated by underground cables the signal levels received at the load ends can be relatively large due to resonance. One significant problem associated with the excessive signal levels is racing digital clocks caused by the additional zero crossings of the mains waveform. This paper presents the results from a detailed modelling study undertaken on a $22 \mathrm{kV}$ system. The dependency of the results on $\mathrm{LV}$ aggregate load models used and the damping provided by the lines and loads are discussed. Mitigation techniques suggested to control excessive signal levels are also investigated.
\end{abstract}

Index Terms-Underground power distribution lines, Interference, Power quality

\section{INTRODUCTION}

Rapidly expanding high density residential areas around Sydney (Australia) tend to be supplied by MV distribution systems that are predominantly underground. This is seen to be quite attractive from many perspectives including power quality and reliability. These residential areas also tend to have electric off-peak hot water heating systems that are controlled by a coded pulse system injected in the form of high frequency sinusoidal ripple signal. One of the major injection frequencies used is $1050 \mathrm{~Hz}$, a frequency that has been in existence for quite a period. The nominal injection period is about 3 minutes. There can also be several injection periods during a day. Although the injected ripple signal is in the order of $4-5 \mathrm{~V}$ rms (referred to the nominal $230 \mathrm{~V} \mathrm{LV}$ level), the signal levels that appear at the LV customer points in some parts of the network have been found to be in excess of $15 \mathrm{~V}$ due to $\mathrm{LC}$ resonance of the line/cable inductance and capacitance. EN50160 [1] specifies a 3 second mean ripple signal level of $5 \%$ or less that is allowed on the network over $99 \%$ of the day. In a nominal $230 \mathrm{~V}$ network this level amounts to $11.5 \mathrm{~V}$ at $1050 \mathrm{~Hz}$.

Zero crossings can appear on the mains waveform depending on the phase angle and magnitude of the ripple

This work was supported by Integral Energy, Huntingwood Drive, Huntingwood, NSW 2148, Australia.

B. S. P. Perera (s.perera(@uow.edu.au), V. J. Gosbel! (v.gosbell@uow.edu.au),S. Elphick (ste01@uow.edu.au) and J. Stones (jis01@uow.edu.au) are with the School of Electrical. Computer and Telecommunications Engineering, University of Wollongong. NSW 2522, Australia.

K. Nguyen (Nguyek@integral.com.au) and N. Browne (Brownen@integral.com.au) are with Integral Energy, Huntingwood Drive. Huntingwood, NSW 2148 Australia. signal. This results in some digital clocks gaining time. The laboratory tests carried out at the University of Wollongong indicate that even the acceptable levels of the ripple signal as low as $4-5 \mathrm{~V}$ can lead to audible noise from ceiling fans which could disturb some customers. The level of audible noise also has shown some dependency on the type of speed controller. The capacitive divider type controllers lead to some attenuation of the noise, while inductive type controllers do not have much of an effect. As expected, with higher signal levels the noise level has been noted to rise significantly. A previous investigation [2] has also reported light flickering caused by a $665 \mathrm{~Hz}$ ripple signal causing rhythm tic voltage levels up to $50 \mathrm{~V}$ superimposed on a $240 \mathrm{~V}, 50 \mathrm{~Hz}$ system.

Distribution network configurations and systems are ever changing and expanding in order to meet the load growth. With a view of understanding the ripple signal amplification behaviour of these networks a project was initiated. Although small scale models have been previously used to investigate problems associated with different networks, it was thought that a more detailed investigation was required, incorporating careful simulation and field measurements as well as feasible means by which the signal levels could be kept under control. This paper reports on the findings of this investigation.

\section{Preliminary simulation Studies}

The network models used in the past were highly simplified versions of relatively extensive networks containing a large number of nodes connected to LV distribution circuits. The assumptions used in the simplification of the network models were quite crude. The representation of the loads was by means of resistances and by largely aggregating the real power, thus ignoring any inductive portions. For the expanded simulation study, due to its versatility and extensive node capability, PSCAD $^{\Phi} /$ EMTDC $^{3 M}$ is used even though the type of study undertaken is primarily a frequency response investigation.

In the new investigation undertaken, the first step was to compare the results of the study network where some ripple signal measurement data was available. With the increased node capability of $\operatorname{PSCAD}^{\circledR} /$ EMTDC $^{\text {TM }}$ the previously simplified study network was expanded back to its most rudimentary form so that the results from the simplified and expanded networks could be compared. In this investigation it was found that the maximum of the average difference between results from the simplified and expanded networks was as high as $18 \%$ with an average difference of $14 \%$ for the three measured nodes on the actual network. The average difference between measured signal level results and the 
results from the simplified network analysis was as high as $16 \%$ with an average difference of $14 \%$. It was also found that the measured results were much closer to the results obtained using the expanded network with a maximum difference of $7 \%$ and an average difference of $5 \%$ for the three measured nodes. It was therefore decided that further modelling be carried out using more expanded network models rather than highly simplified models.

\section{DETARED MODELLING AND SIMULATION STUDIES}

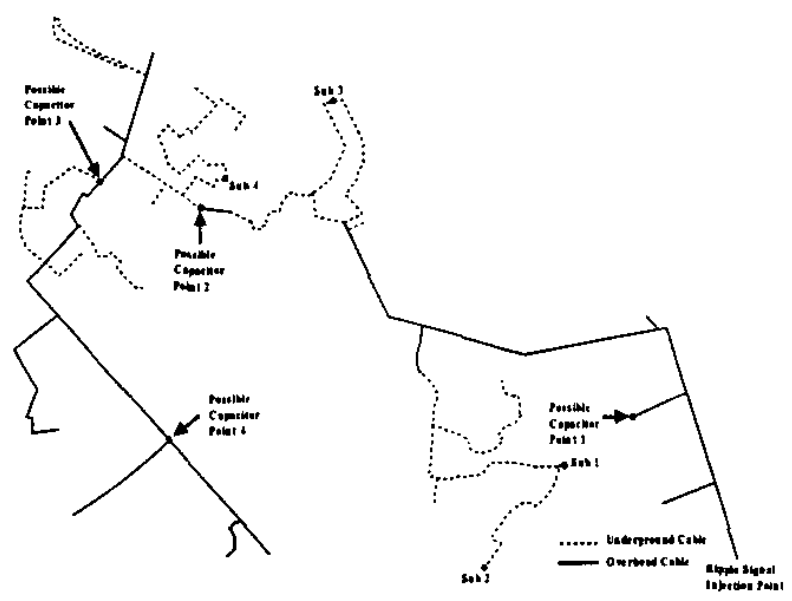

Fig. 1. Layout of the $22 \mathrm{kV}$ network under investigation

\section{A. Description of the network}

The layout of the investigated $22 \mathrm{kV}$ network is shown in Fig. 1. The $1050 \mathrm{~Hz}$ injection point is at the zone substation where it is injected on to the $11 \mathrm{kV}$ bus and an $11 \mathrm{kV} / 22 \mathrm{kV}$ auto transformer is used for stepping up. The $11 \mathrm{kV}$ bus supplies several other radial feeders but in this study they were ignored. As can be seen, the network contains a substantial proportion of underground distribution cables in comparison to overhead lines. The total maximum demand of the feeder is about 9MVA whereas the capacity of the feeder is about 12MVA. The LV customers are connected to the $22 \mathrm{kV}$ network via some 44 pad mounted and pole mounted transformers that are scattered throughout the network. The measurement points (Sub 1 - Sub 4) indicated in Fig. 1 represent padmount substations where measurements could be easily carried out. It also shows points where overhead access was available for placement of capacitor banks on pole tops.

\section{B. Basic assumptions}

Following are some of the key assumptions made in the network modelling:

1. Single-phase representation assuming balanced operation

2. Ripple signal can be represented by an ideal voltage source and any loading due to other feeders and the HV network are negligible

3. Lumped network models are adequate to represent overhead and underground line sections as the maximum physical length involved is much less than $71 \mathrm{~km}$, the $1 / 4$ wave length at $1050 \mathrm{~Hz}$

4. High frequency correction of resistive elements of the model at $1050 \mathrm{~Hz}$ is to be initially neglected

5. All transformers can be represented using a series inductance

6. The aggregation of all LV loads can be represented using lumped passive networks of choice at the padmount and pole mount transformers and have a uniform power factor. The LV side cable capacitances were aiso ignored.

In order to justify some of the above assumptions measurements were carried out on the LV side of selected padmount stations under normal operating conditions. These measurements indicate that there is some degree of unbalance in the current together with a significant harmonic content as illustrated by waveform captures of Fig. 2 . These waveforms suggest that the single-phase representation of the network and representation of the aggregate loads by a passive network are somewhat questionable.
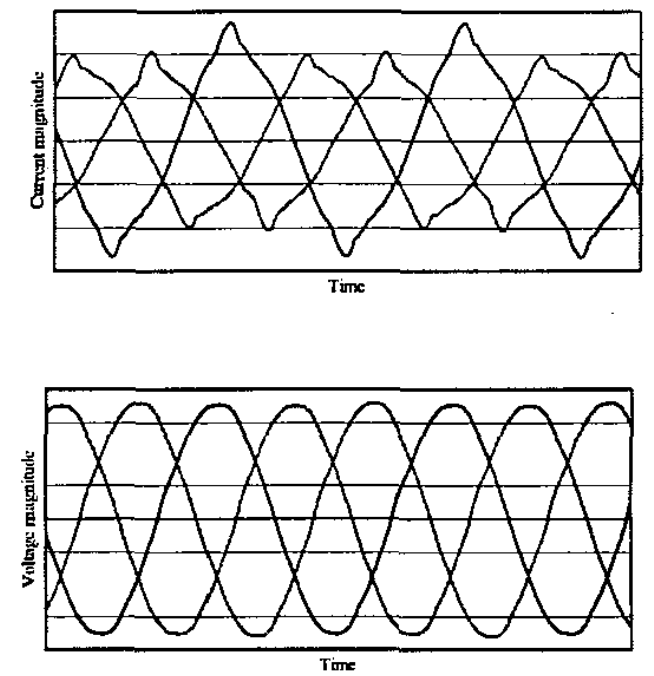

Fig. 2 Waveforms of measured three phase currents (top) and voltages (bottom) at a substation during heavy load

Power factor at all measured substations indicated that it is around 0.8 lagging. This was also the case at the zone substation.

\section{Representation of aggregate loads}

The development of an appropriate passive network that can represent the true behaviour of aggregate LV loads was a major task. Although the knowledge of the total load and overall power factor can be used to derive a series or a parallel R-L equivalent network [2], this representation will not behave in the correct manner when the frequency of study is significantly higher than the fundamental frequency. A series R-L equivalent circuit, as expected will not represent the true damping at the high frequencies whereas a parallel R-L equivalent will provide more than the true damping that is 
present. Considering the motor type loads such as refrigerator compressor motors which are series $R-L$ types and pure $R$ type resistive type loads such as electric ovens and hot water heaters the aggregate load is better represented by a hybrid circuit as shown in Fig. 3. This assumes that the non-linear portion of the loads is represented by the same passive circuit.

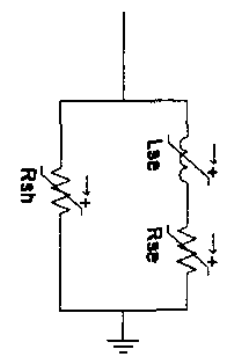

Fig. 3 Hybrid load model

The way in which the total real power $\mathrm{P}$ (calculated using load kVA and power factor) at a distribution substation be apportioned to the two branches of the circuit of Fig. 3 needs to be determined. PSCAD ${ }^{\circledR} /$ EMTDC $^{\mathrm{TM}}$ model was developed such that a fraction $x$ of the total real power $P$ at a substation is represented by $\mathrm{Rsh}$ and hence $(1-\mathrm{x}) \mathrm{P}$ is represented by Rse. This fraction $x$ (called the allocation ratio) can be an external global parameter that can be adjusted so that various ratios can be tried out. It is not practical to change this ratio independently for the different aggregated loads and hence the same ratio is used uniformly across the network model. As seen in Fig. 4, the calculation of the two variable resistors (Rse and Rsh) and the variable inductor (Lse) can be automated using standard blocks implementing (1) - (5). This calculation is based on the total load at distribution substation $(\mathrm{kVA})$, assumed power factor and the allocation ratio. Further inputs to this calculation are the kVA loading level at a substation as a fraction of the maximum specified (ie. enabling light load and heavy load study) and high frequency skin effect correction to adjust the resistive components at appropriate stages of the simulation.

$$
R_{s h}=\frac{k V^{2}}{x P}
$$

The apparent voltamperes of the series R-L branch is given by:

$$
S_{s e}=\sqrt{[(1-x) P]^{2}+Q^{2}}
$$

and hence the impedance of the series $\mathrm{R}-\mathrm{L}$ branch is

$Z_{s e}=\frac{k V^{2}}{S_{s e}}$

Therefore, the series $\mathrm{R}-\mathrm{L}$ branch is defined by

$$
\begin{aligned}
& R_{s e}=Z_{s c} \cos \theta_{1} \\
& X_{s e}=Z_{s e} \sin \theta_{1}
\end{aligned}
$$

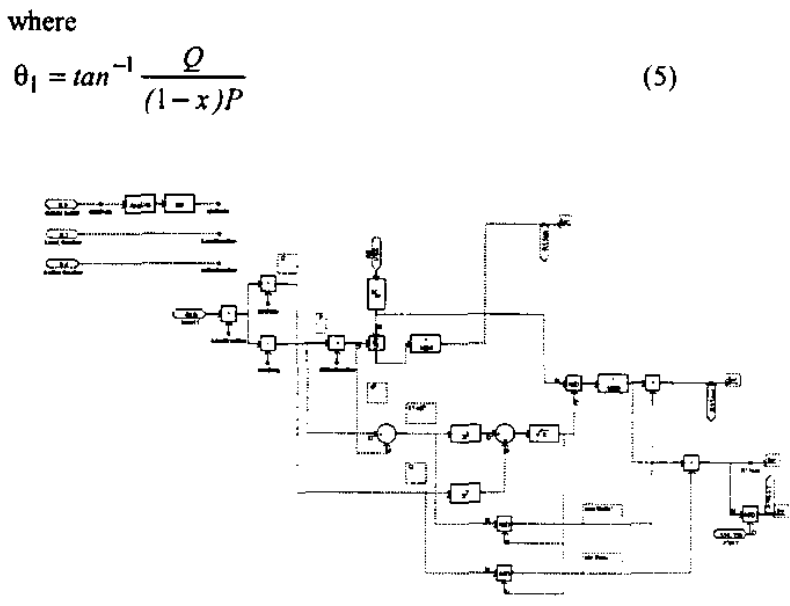

Fig 4 . PSCAD ${ }^{\oplus} /$ EMTDC $^{\top M}$ calculation of parameters of the hybrid load model components

\section{Representation of overhead and cable sections}

Overhead lines were represented using lumped series R-L networks and the cable sections were represented using nominal $\pi$ networks. Provision was made to allow for any high frequency correction of the line resistances.

\section{E. Field measurement procedure}

In order to validate the accuracy of the simulation model results field measurements were carried out when the zone substation load was nearly peak ( $70 \%$ of MDI) and during off peak periods ( $28 \%$ of MDI). Four harmonic analysers located at different distribution substations (Fig. 1) were set up so that they could $\log$ the L-N voltage waveform on the LV side simultaneously during the $1050 \mathrm{~Hz}$ injection period.

\section{DETAILED SIMULATION RESUlTS}

\section{A. Resonance curves}

With the network setup on PSCAD ${ }^{*} /$ EMTDC $^{\text {TM }}$, frequency scans were carried out to find the resonance curves under light and heavy load conditions for different values of $x$. No correction factors were applied to account for the high frequency effects on the lines or the loads. Fig. 5 shows a typical resonance curve for one of the substations. The behaviour of the model with $x=0 \%$ (i.e. a pure series $R-L$ circuit), is quite different to that with $x=100 \%$ (i.e. pure parallel R-L circuit). This suggests that load modeling and hence damping plays a vital role in controlling the level of signal amplification throughout the frequency range tested, including the injection frequency of $1050 \mathrm{~Hz}$. However, the resonance frequency (around $950 \mathrm{~Hz}$ ) is virtually unaffected by the value of $\mathrm{x}$ whether it is light or heavy load.

\section{B. Signal amplification levels}

For the four substations considered above the signal amplification levels obtained by simulation are given in Tables I and II for both light and heavy load conditions at the injection frequency (with no high frequency correction). From 
these readings it is seen again that the value of $x$ has a significant influence on the simulation results.
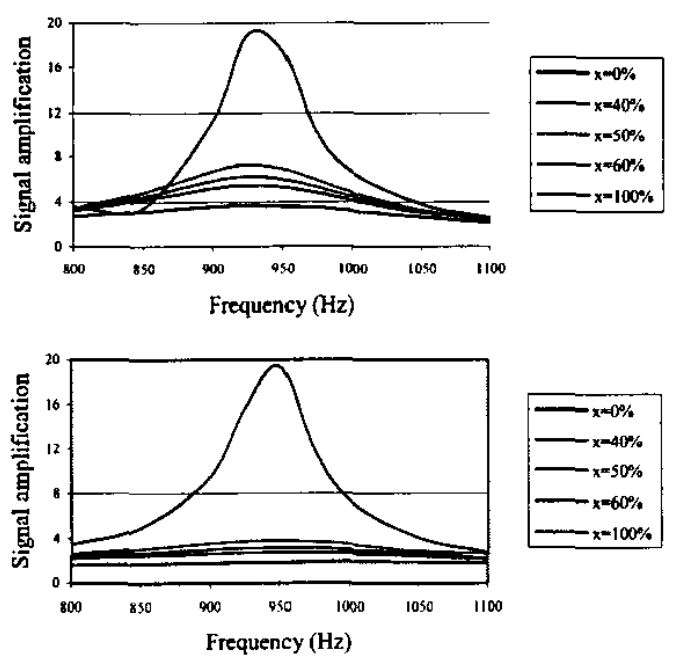

Fig. 5 . Resonance curves under light (top) and heavy load (bottom) conditions with variable $x$

TABLE I

AMPLIFICATION LEVELS AT 10SOHZ UNDER LIGHT LOAD CONDITIONS

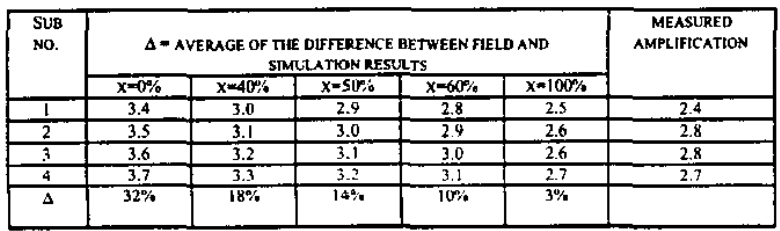

TABLE II

AMPLIFICATION LEVELS AT 105OHZ UNDER HEAVY LOND CONDITIONS

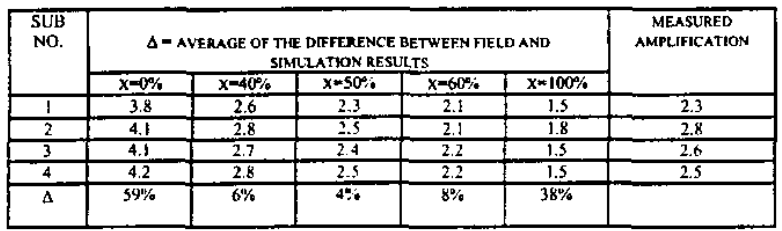

From these tables it is evident that, while there is a significant level of $1050 \mathrm{~Hz}$ signal amplification, under light load conditions there is better agreement between simulation results and field measurements when the value of $x$ is closer to $100 \%(\Delta=3 \%$ in Table I) whereas under heavy load conditions the agreement is better when $\mathrm{x}$ is around $50 \%$ $(\Delta=4 \%$ in Table II). This observation tends to suggest that the nature of the load changes such that under light load conditions the loads are more pure $\mathrm{R}$ types whereas under heavy load conditions there is a good blend of the pure $R$ type and series R-L type loads acting in shunt, further supporting the use of a hybrid load model as shown in Fig. 3. Considering the nature of loads that are connected to residential distribution systems, the aggregate load at a distribution substation is better represented by a hybrid model with $\mathrm{x}=50 \%$ (as experience suggested) in all simulations which implies that there is a good blend of pure $R$ type loads such as hot water heaters, electric stoves and R-L type loads such as refrigerator compressor motors and air conditioners.

Simulations were also carried out to examine the effect of high frequency correction on line conductors and load resistive parts. Although there are correction factors that can be applied to account for skin effect on conductors [3] these factors apply to overhead systems with voltages above $132 \mathrm{kV}$. At a frequency of $1050 \mathrm{~Hz}$ the suggested factor is about 1.7 . One of the suggested correction factors for passive loads is given by $\sqrt{h}$ where $h$ is the harmonic order. Only a single correction factor given by $V_{h}(=4.6)$ was applied in further simulation studies to both the line resistances and load resistive parts. There is some degree of uncertainty in this correction factor. The summary of these simulations is given in Figs. $6 \& 7$. From these figures it is evident that when only the line correction is applied the level of amplification decreases whereas when only the load correction is applied the level of amplification increases. Any load correction is equivalent to the reduced damping provided under light load conditions in comparison to heavy load conditions. When both Iine and load are corrected the level of amplification reaches a value in between the above two values.

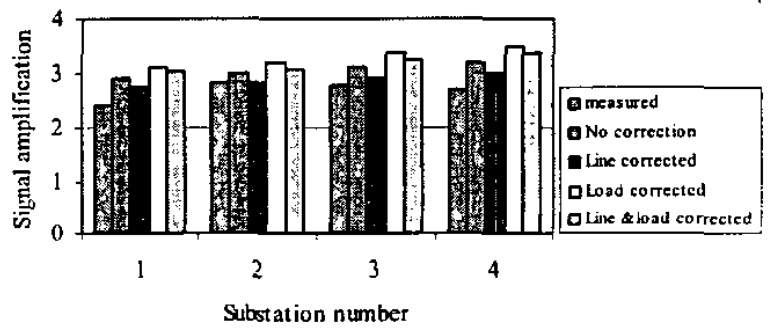

Fig. 6 Variation of signal amplification levels - light load

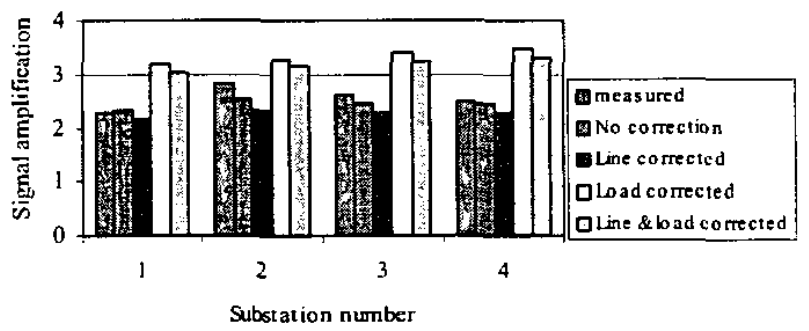

Fig. 7 Variation of signal amplification levels - heavy load

Further, it is seen that the high frequency correction for load makes a marked difference to the simulation results under heavy load conditions compared to what happens under light load conditions. This throws some doubt on the validity of such a correction being applied to loads. It is also seen that the line high frequency correction, although seemingly on the 
high side (factor of 4.6) tends to give simulation results that are much closer to what is experimentally observed.

\section{MITIGATION ISSUES AND SUBSEQUENT SIGNAL AMPLIFICATION LEVELS}

The next step was to investigate the various mitigation techniques as the measured signal levels were considered high $(>12 \mathrm{~V})$. Some of the mitigation techniques suggested [2] are the use of series reactors, tuned filters and capacitors. The investigated network also offered the possibility of reconfiguration to minimize the signal amplification.

Out of these techniques one of the most promising options was the connection of shunt capacitors (although an expensive option) as this would yield a resonance frequency which is less than the current value $(950 \mathrm{~Hz})$. As the capacitors have to be left permanently connected to the network it must be ensured that they allow normal $50 \mathrm{~Hz}$ operation without causing voltage problems. Also they should mitigate the $1050 \mathrm{~Hz}$ amplification both at light load and heavy load, light load being the more critical case. There was also a concern that connection of capacitors would load the $1050 \mathrm{~Hz}$ injection unit above its capacity.

The value of the capacitance $(0.75 \mu \mathrm{F}-1.25 \mu \mathrm{F})$ to be connected to the network was based on a kVA rating which is a fraction of the light load demand at the zone substation with the fundamental voltage profile in mind. However, the point of connection of this capacitor is not governed by any simple rule and hence it was decided to test these points by trial and error. It is possible to have the capacitors distributed around the network as well. The possible points of connection are indicated in Fig. 1 which correspond to pole tops.

A general observation in the simulation studies was that as a capacitor bank is moved away from the injection point it becomes more effective in controlling the signal levels throughout the network. Point 4 of Fig. 1 was chosen for the connection of the capacitor bank by trial and error as it gave the most desirable reduction in the signal level. With increasing capacitor values the amplification level decreased further, even below unity. The results that were obtained by distributing a lumped capacitor into several locations did not produce results that were significantly different to the above.

Figs. 8 and 9 illustrate the reduction of the signal amplification when a $0.75 \mu \mathrm{F}$ capacitor bank is connected at point 4 under both light and heavy load conditions. It can also be noted that the line and load high frequency correction has very little influence on the simulation results when the capacitor bank is connected indicating that the new resonance frequency (of $850 \mathrm{~Hz}$ ) is further away from the $1050 \mathrm{~Hz}$.

Simulations carried out with no connected capacitors indicated that the injection unit loading levels are in the ratio 1.25: 1.0 between light and heavy load confirming the high signal amplification levels that prevail at light load compared to heavy load. When the capacitor bank is connected the loading level on the injection unit decreased further by nearly $37 \%$ when compared to the loading level under light load.

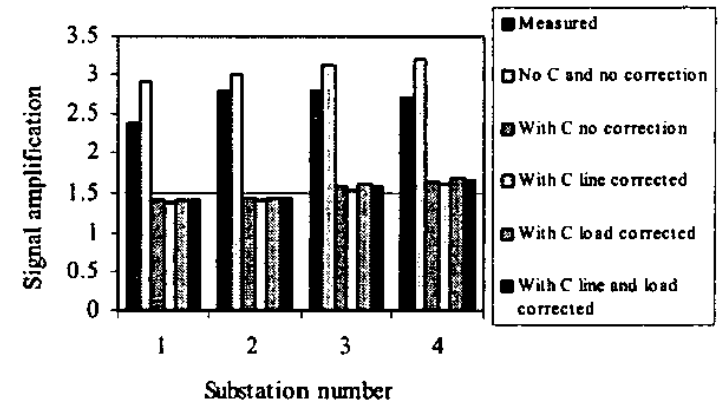

Fig. 8 Signal amplification levels under light load with $0.75 \mu \mathrm{F}$ capacitor connected at point 4

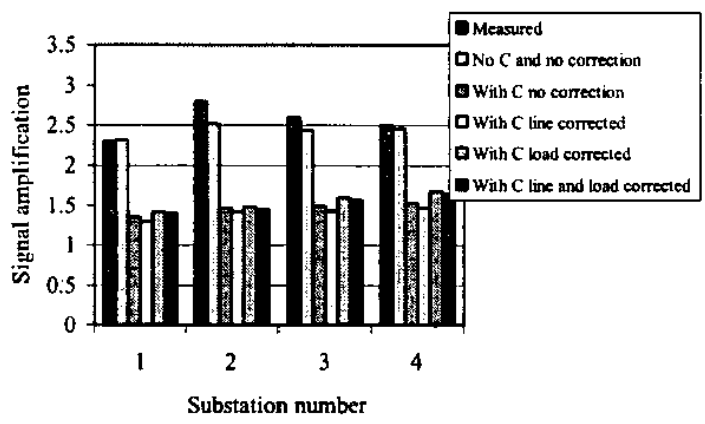

Fig. 9 Signal amplification levels under heavy load with $0.75 \mu \mathrm{F}$ capacitor connected at point 4

As the connection of capacitors was considered to be an expensive option, reconfiguring the network was next considered. In the reconfiguring work some open points were formed and more underground cables were connected to the network. This system was then analysed using the same modelling techniques as already described. The new resonance frequency was found to be around $800 \mathrm{~Hz}$ compared to the resonance frequency of $950 \mathrm{~Hz}$ prior to the reconfiguration. As a result the signal amplification levels were found to be much less than what was previously observed. Field measurements were also cartied out where it was found that these readings are in close agreement with the results from the simulation.

For network planning purposes, the ultimate network configuration was also modelled. In this configuration, a substantial portion of the underground cables will be moved to other feeder networks. Once the planned network changes to meet the load growth in the area are implemented the resonance frequency will increase up to $1500 \mathrm{~Hz}$. This means that at some stage in the future the resonant frequency will cross $1050 \mathrm{~Hz}$. Care will therefore need to be taken to ensure that any interim network arrangement does not cause the resonance frequency to lie close to $1050 \mathrm{~Hz}$. 


\section{CONCLUSIONS}

The paper has presented a case study in relation to the excessive amplification of ripple frequency signals in a distribution system containing a large proportion of underground cabies. The problem has arisen as a result of recent network expansion and under grounding and adherence to a ripple signal injection system that has been in existence for many years.

Modelling of the MV distribution network to study the problem has been found to be quite tedious due to its extent and the assumptions involved. Even after making reasonable assumptions fine tuning is required to reach reasonable agreement between field measurements and results from the simulation. The damping provided by the line resistances was found to be an important component in reaching this agreement in addition to representation of the LV loads by an aggregate model. A hybrid model that is suitable for simulating the aggregate LV loads has been presented. However, further research is required to develop load models based on measurements that will account for modern day nonlinear equipment. Further work is also required to develop high frequency correction factors for overhead lines and underground cable systems.

Connection of additional capacitors to the MV network has been investigated with a view to move the resonance frequency further away from the signal frequency. It has been found that this option would be quite successful in controlling the signal levels within acceptable limits. Although this is the case, a much cheaper option of network reconfiguration was possible to reduce the signal amplification levels. It has been shown that the modeling techniques discussed could be adopted in furure to examine the effects of reconfiguring and network expansion on ripple signal amplification.

\section{REFERENCES}

[1] EN50160: European Standard. Voltage characteristics of electricity supplied by public distribution systems. 1999.

[2] T. B. Norris, P. S. Bodger, "Ripple control signal interference due to a lightly loaded rural distribution line", IEE Proc., Vol.136. Pt C. No. 6, Nov. 1989.

[3] J. Arrillaga, B.C. Smith. N. R. Watson, A. R. Wood, Pow'er System Harmonic Analysis. John Wiley, 1997.

\section{BIOGRAPHIES}

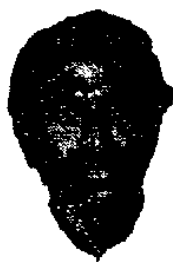

Sarath Perera (M'1995): Dr Perera graduated from the University of Moratuwa, Sri Lanka with a BSc (Eng) degree (1974) specialising in Electrical Power Engineering. He obtained his MEngSc degree (1978) from the University of New South Wales and the PhD degree (1988) from the University of Woilongong. He is now a Senior Lecturer at the University of Wollongong. His research interests are in the area of Power Quality.
Kim Nguyen: Miss Nguyen graduated from the University of Western Sydney in 1999 under a Cadetship Program sponsored by Integral Energy where she is now an Engineer. Currently she is with the Asset Management branch where she is involved in making recommendations on remedial solutions to customer supply problems and apply relevant standards. policies and guidelines. She is a Member of the Institution of Engineers, Australia.

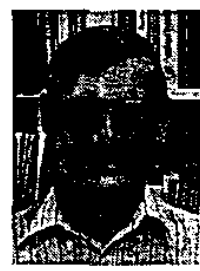

Vic Gosbell (M'1975): Dr Gosbell obtained his BE degree in 1966 and his $\mathrm{PhD}$ in 1971 from the University of Sydney. In 1973 he commenced lecturing at the University of Sydney and in 1990 took up a position of Associate Professor at the University of Wollongong where he is now the Professor of Power Engineering. His research interests are in power electronic simulation, hamonics and power quality. $\mathrm{He}$ is a Fellow of the Institution of Engineers. Australia and the immediate past Chaimerson of the Austraiasian Committee for Power Engineering.

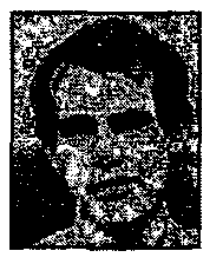

Neil Browne (M'1988): Neil Browne is an Engineer with Integral Energy's System Development Branch. He received his Bachelor of Engineering Degree from the University of New South Wales in 1976. He is involved in protection, policy, operational analysis and power quality control and monitoring.

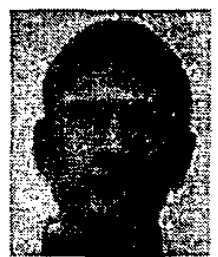

Sean Elphick: Mr Elphick is a final year undergraduate student at the University of Wollongong specialising in Electrical Engineering.

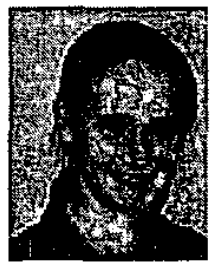

Jessica Stones (S'1999): Miss Stones is a final year undergraduate student at the University of Wollongong specialising in Electrical Engineering. She holds an Integral Energy sponsored scholarship. 